Research Article

\title{
In Vitro Schistosomicidal Activity of the Alkaloid-Rich Fraction from Ruta graveolens $L$. (Rutaceae) and Its Characterization by UPLC-QTOF-MS
}

\author{
Lara Soares Aleixo de Carvalho ${ }^{(D},{ }^{1}$ Lucas Sales Queiroz, ${ }^{1}$ Ismael José Alves Junior, \\ Ayla das Chagas Almeida, ${ }^{2}$ Elaine Soares Coimbra, ${ }^{2}$ Priscila de Faria Pinto ${ }^{3}{ }^{3}$ \\ Marcos Paulo Nascimento da Silva, ${ }^{4}$ Josué De Moraes, ${ }^{4}$ and Ademar A. Da Silva Filho (iD ${ }^{1}$ \\ ${ }^{1}$ Faculty of Pharmacy, Department of Pharmaceutical Sciences, Federal University of Juiz de Fora, Juiz de Fora, \\ MG 36036-900, Brazil \\ ${ }^{2}$ Department of Parasitology, Microbiology and Immunology, Biological Sciences Institute, Federal University of Juiz de Fora, \\ Juiz de Fora, MG 36036-900, Brazil \\ ${ }^{3}$ Department of Biochemistry, Biological Sciences Institute, Federal University of Juiz de Fora, Juiz de Fora, MG 36036-900, Brazil \\ ${ }^{4}$ Núcleo de Pesquisa em Doenças Negligenciadas, Universidade de Guarulhos, Guarulhos, SP 07025-000, Brazil
}

Correspondence should be addressed to Ademar A. Da Silva Filho; ademar.alves@ufjf.edu.br

Received 13 May 2019; Revised 9 September 2019; Accepted 31 October 2019; Published 16 November 2019

Academic Editor: Marco Leonti

Copyright (c) 2019 Lara Soares Aleixo de Carvalho et al. This is an open access article distributed under the Creative Commons Attribution License, which permits unrestricted use, distribution, and reproduction in any medium, provided the original work is properly cited.

\begin{abstract}
Schistosomiasis is a neglected tropical disease that affects million people worldwide, mostly in developing countries. Ruta graveolens (Rutaceae) is a plant used in folk medicine to treat several diseases, including parasitic infections. In this study, we reported the in vitro schistosomicidal activity of the $R$. graveolens extract $(\mathbf{R g})$ and its active fraction (Rg-FAE). Also, the characterization of Rg-FAE by UPLC-ESI-QTOF-MS analysis and its in vitro antileishmanial activity against Leishmania braziliensis were also performed. In vitro schistosomicidal assays were assessed against adult worms of $S$. mansoni, while cell viability against peritoneal macrophages was measured by MTT assay. Rg $(100 \mu \mathrm{g} / \mathrm{mL})$ exhibited noticeable schistosomicidal activity, causing $100 \%$ mortality and decreasing motor activity of all adult male and female schistosomes, but with low activity against L. braziliensis. After chromatographic fractionation of $\mathbf{R g}$, fraction Rg-FAE was obtained, showing high activity against adult schistosomes. UPLC-ESI-QTOF-MS analysis of Rg-FAE revealed the presence of eleven alkaloids and one furanocoumarin. No significant antileishmanial activity was found for Rg, while Rg-FAE exhibited activity against L. braziliensis promastigotes. We demonstrated, for the first time, that the $R$. graveolens extract $(\mathbf{R g})$ and its alkaloid-rich fraction (Rg-FAE) are active against adult worms of $S$. mansoni, with no significant cytotoxicity on macrophages. Our findings open the route to further antiparasitic studies with the active fraction of $R$. graveolens and its identified compounds, especially alkaloids.
\end{abstract}

\section{Introduction}

Schistosomiasis is a neglected tropical disease (NTD) caused by Schistosoma parasites, mainly S. mansoni, that is associated with long-term undernutrition, anaemia, organ scarring, and fibrosis, resulting in disabling patient symptoms [1]. About 190 million people are infected worldwide with Schistosoma infections, with more than 70 million of new cases and thousands of deaths annually registered [2].
Only in Brazil, around 8 million people are infected with this chronic debilitating disease [3]. However, the treatment of schistosomiasis is based on only one drug, praziquantel (PZQ), which has a limited effect on already developed liver and spleen lesions [4].

Leishmaniasis, also a NTD, is caused by the protozoan Leishmania and transmitted by infected female phlebotomine sand flies. Leishmaniasis is endemic in more than 95 countries of tropical and subtropical areas, with more than 1 million of 
cases worldwide every year [5]. Although some antileishmanial compounds have been registered as medications, such as amphotericin B, pentamidine, and miltefosine, none of the available drugs can be considered perfect because of their high toxicity, long duration of treatment, and severe adverse reactions, which often lead to treatment abandonment [5]. In this scenario, there is an urgent need for new and better antileishmanial drugs $[5,6]$.

In this regard, Ruta graveolens (Rutaceae), also known as "rue," has been used in the folklore medicine for the treatment of several inflammatory diseases, such as rheumatism [7], and also to treat cutaneous leishmaniasis [8, 9] in Brazil. Previous studies showed that R. graveolens exhibits antiparasitic activity against Leishmania amazonensis [9] and contains several biologically active metabolites, such as alkaloids and coumarins [8, 10]. Meanwhile, neither schistosomicidal studies nor antileishmanial activities against Leishmania braziliensis has not yet been described to R. graveolens.

Thus, the aim of this study was to evaluate the in vitro schistosomicidal activities of the hydroalcoholic extract and the alkaloid-rich fraction from $R$. graveolens. Also, the characterization of the alkaloid-rich fraction from $R$. graveolens by UPLC-ESI-QTOF-MS analysis and its in vitro antileishmanial activity against Leishmania braziliensis were also performed.

\section{Materials and Methods}

2.1. Plant Material and Extraction. Aerial parts of $R$. graveolens L. were collected at the Faculty of Pharmacy's Medicinal Herb Garden, Juiz de Fora city, MG, Brazil, in January, 2017. A voucher specimen (CESJ 70472) was identified and stored at the Herbarium of the Botany Department of the Federal University of Juiz de Fora, MG, Brazil.

Plant material (250 g) was dried, powdered, and exhaustively extracted by maceration at room temperature, using EtOH : $\mathrm{H}_{2} \mathrm{O}(8: 2 \mathrm{v} / \mathrm{v})$. After filtration, the solvent was removed under reduced pressure to yield $25 \mathrm{~g}$ of the crude hydroalcoholic extract of $R$. graveolens ( $\mathbf{g g})$. The crude extract of $R$. graveolens ( $\mathbf{R g}$ ) (22 g) was chromatographed over silica gel (70-230 mesh, Merck) using a vacuum liquid chromatography system (VLC, glass columns with $5-10 \mathrm{~cm}$ i.d) and hexane-ethyl acetate mixtures in increasing proportions as eluents, furnishing 4 fractions: Rg-FC1 (960 mg), Rg-FC2 (220 mg), Rg-FC3 (670 mg), and Rg-FAE $(1700 \mathrm{mg})$. Based on its schistosomicidal and antileishmanial activities, fraction Rg-FAE was selected for UPLC-ESIQTOF-MS analysis.

\subsection{UPLC-ESI-QTOF-MS Analysis}

2.2.1. LC Conditions. The ultraperformance liquid chromatograph (UPLC) analysis was carried out, using an Acquity UPLC system (Waters Corporation, Milford, MA, USA) equipped with a binary pump, inline degasser, and autosampler coupled to an electrospray ionization quadrupole time-of-flight tandem mass spectrometer (ESI-Q-
TOF/MS) (Waters Corporation, USA). Separation was carried out on $\mathrm{BEH} \mathrm{C}_{18}$ column $(100 \mathrm{~mm} \times 2.1 \mathrm{~mm}, 1.7 \mu \mathrm{m}$, Milford, USA). The mobile phase consisted of LC grade water with $0.1 \%$ formic acid (A) and LC grade acetonitrile (B) with the following gradient profiles: $0-2 \mathrm{~min}, 5 \% \mathrm{~B}$; 2-14 min, 5-98\% B; $14-16 \mathrm{~min}, 98 \% \mathrm{~B}$; and $16-20 \mathrm{~min}$, $98-5 \%$ B. The flow rate was $0.4 \mathrm{~mL} \cdot \mathrm{min}^{-1}$. Before the analysis, samples were dissolved in methanol $\left(10 \mathrm{mg} \cdot \mathrm{mL}^{-1}\right)$, centrifuged at $10,000 \mathrm{rpm}$, filtered using a $0.22 \mu \mathrm{m}$ filter, and injected (injection volume of $15 \mu \mathrm{L}$ ).

2.2.2. MS Conditions. Mass spectrometry was performed with a XEVO G2S QTOF mass spectrometer (Waters Corporation, Milford, MA, USA) with ESI operating in the positive ion mode for scanning. The scanning range was $\mathrm{m} / \mathrm{z}$ 150-1200. The capillary voltage was $2.5 \mathrm{kV}$, the low collision energy was $6 \mathrm{eV}$, and the higher collision energy was 15$30 \mathrm{eV}$. The ion source temperature was $120^{\circ} \mathrm{C}$, and the desolvation temperature was $450^{\circ} \mathrm{C}$. Nitrogen was used as the source of desolvation gas $\left(800 \mathrm{~L} \cdot \mathrm{h}^{-1}\right)$ and cone gas $\left(50 \mathrm{~L} \cdot \mathrm{h}^{-1}\right)$. For accurate mass measurements, data were centroided during acquisition, and $200 \mathrm{pg} \cdot \mathrm{mL}^{-1}$ of leucineenkephalin ( $m / z$ 565.2771) (Sigma-Aldrich, Steinheim, Germany), dissolved in acetonitrile/ $0.1 \%$ formic acid (50: $50, \mathrm{v} / \mathrm{v})$, was infused continuously as an external reference (LockSpray $^{\mathrm{TM}}$ ) into the ESI source with automatic mass correction enabled. The data were processed using Chromalynx $^{\mathrm{TM}}$ application manager with MassLynx ${ }^{\mathrm{TM}} 4.1$ software (Waters Corporation, Milford, MA, USA). Besides the observed MS spectra and data obtained by QTOF-MS analysis, the main tools for compound identification were the interpretation of the observed QTOF-MS spectra in comparison with those found in the literature and several online databases (ChemSpider, MassBank, and Spectral Database for Organic Compounds).

\subsection{Schistosomicidal Assays}

2.3.1. Parasite. Schistosoma mansoni (BH strain) worms were maintained in Biomphalaria glabrata snails as intermediate hosts and Mesocricetus auratus hamsters as definitive host at the Adolfo Lutz Institute (São Paulo, Brazil), according to standard procedures previously described [11]. At 49 days after infection, adult $S$. mansoni specimens were recovered from each hamster by perfusion in the Roswell Park Memorial Institute (RPMI) 1640 medium (Invitrogen, So Paulo, Brazil) and supplemented with heparin. All experiments were authorized by the Committee for Ethics in Animal Care of Adolfo Lutz Institute (São Paulo, Brazil), in accordance with nationally and internationally accepted principles for laboratory animal use and care (CEUA $\neq 11.794 / 08)$. The study was conducted in adherence to the institution's guidelines for animal husbandry.

2.3.2. In Vitro Studies with S. mansoni. Adult schistosomes were washed in the RPMI 1640 medium (Gibco) and supplemented with $200 \mu \mathrm{g} / \mathrm{mL}$ streptomycin, $200 \mathrm{IU} / \mathrm{mL}$ 
penicillin (Invitrogen), and $25 \mathrm{mM}$ Hepes. Adult worm pairs (male and female) were incubated in a 24-well culture plate (Techno Plastic Products, TPP, St. Louis, MO, USA), containing the same medium supplemented with $10 \%$ heatinactivated calf serum (Gibco BRL) at $37^{\circ} \mathrm{C}$ in a $5 \% \mathrm{CO}_{2}$ atmosphere. For the in vitro test with $\mathrm{S}$. mansoni, a preliminary screening of the crude extract $(\mathbf{R g})$ and its fractions Rg-FC1, Rg-FC2, Rg-FC3, and Rg-FAE were evaluated at $100 \mu \mathrm{g} / \mathrm{mL}$, according to previously described [12]. The most active sample (Rg-FAE) was also evaluated at lower concentrations ( 3.125 to $50 \mu \mathrm{g} / \mathrm{mL}$ ). Samples were added to the culture from a $4000 \mu \mathrm{g} / \mathrm{mL}$ stock solution in RPMI 1640 , containing dimethyl sulfoxide (DMSO). The final volume in each well was $2 \mathrm{~mL}$. The control worms were assayed in the RPMI 1640 medium, and RPMI 1640 with $0.5 \%$ DMSO as control group and PZQ $(2 \mu \mathrm{M})$ was used as the reference drug. All experiments were performed in triplicate and were repeated at least two times. Parasites were maintained for $72 \mathrm{~h}$ and monitored every $24 \mathrm{~h}$ using a light microscope in order to evaluate their general conditions, such as motor activity and mortality rate [13].

\subsection{Antileishmanial Assays}

2.4.1. Parasite Culture. Promastigotes of L. braziliensis (MHOM/Br/75/M2903) were cultivated in the BHI medium (Himedia, Mumbai, India) supplemented with $10 \%$ inactivated fetal bovine serum (FBS) (Cultilab, So Paulo, Brazil), L-glutamine, penicillin at $100 \mathrm{UI} / \mathrm{mL}$, and streptomycin at $100 \mu \mathrm{g} / \mathrm{mL}$ (Cultilab, So Paulo, Brazil) and kept in a BOD incubator at $25^{\circ} \mathrm{C}$.

2.4.2. In Vitro Antileishmanial Activities. Promastigotes of L. braziliensis, at $2 \times 10^{6}$ cells $/ \mathrm{mL}$, were incubated with different concentrations $(3.125$ to $50.0 \mu \mathrm{g} / \mathrm{mL}$ ) of the $R$. graveolens crude extract $(\mathbf{R g})$ or its alkaloid-rich fraction (Rg-FAE) for $72 \mathrm{~h}$ at $25^{\circ} \mathrm{C}$, according to previously described [14]. Parasite viability was evaluated by MTT assay, and percentages of the inhibition growth were expressed in comparison with untreated control. For the intracellular amastigote assays, peritoneal macrophages, obtained from $\mathrm{BALB} / \mathrm{c}$ mice, were added in the RPMI 1640 medium (Cultilab, So Paulo, Brazil) supplemented with $10 \%$ FBS at $2 \times 10^{6}$ cells $/ \mathrm{mL}$. Adherent macrophages were infected with L. braziliensis promastigotes in the stationary growth phase $(\mathrm{MOI}=10)$ and incubated for $4 \mathrm{~h}$ in $5 \% \mathrm{CO}_{2}$ at $33^{\circ} \mathrm{C}$. After washing, various concentrations $(6.25$ to $50.0 \mu \mathrm{g} / \mathrm{mL})$ of the $R$. graveolens crude extract $(\mathbf{R g})$ or its alkaloid-rich fraction (Rg-FAE) were added for $72 \mathrm{~h}$, according to previously described [14]. The slides were stained with Giemsa, and the number of amastigotes was determined using light microscopy. The results were expressed in percentage of inhibition of the number of amastigotes, compared with untreated control. All procedures were performed in agreement with the Ethical Principles in Animal Research and according to protocols approved by the Ethical Committee for Animal Research (CEUA $\neq 012 / 2015)$.
2.5. Cytotoxicity Assay. Peritoneal macrophages obtained from $\mathrm{BALB} / \mathrm{c}$ mice were treated with different concentrations ( 4.69 at $75.0 \mu \mathrm{g} / \mathrm{mL}$ ) of the $R$. graveolens crude extract (Rg) and its alkaloid-rich fraction (Rg-FAE) for 72h, according to previously described [14]. Results were determined by MTT assay, and all procedures were performed in agreement with the Ethical Principles in Animal Research and according to protocols approved by the Ethical Committee for Animal Research (CEUA $\neq 013 / 2015)$.

2.6. Statistical Analysis. Statistical tests were performed with the Graphpad Prism (version 4.0) software. Significant differences were determined by one-way analysis of variance (ANOVA) and applying Tukey's test for multiple comparisons with a level of significance set at $P<0.05$.

\section{Results and Discussion}

The demand for new therapeutic alternatives against the 20 groups of the so-called NTDs is a worldwide need since the few drugs available are often associated with severe side effects and high toxicity $[1,6,15]$. In this context, plantderived natural products constitute a quite important starting point for new therapies or for the development of new drugs against NTDs, due to their vast chemical diversity and already known antiparasitic potential [15].

Considering the promising antiparasitic potential of Rutaceae species, in this work, we have highlighted the antischistosomal activity of an alkaloid-rich fraction from the R. graveolens extract. To our knowledge, this is the first report for the schistosomicidal activity of $R$. graveolens against adult worms of $S$. mansoni. Also, we have evaluated the antileishmanial activity of $R$. graveolens against $L$. braziliensis, which has not been documented in the literature.

First, the survival and motor activities of $S$. mansoni adult worms, after in vitro incubation with the crude extract of $R$. graveolens $(\mathbf{R g})$, were analyzed. As shown in Table $1, \mathbf{R g}$ $(100 \mu \mathrm{g} / \mathrm{mL})$ exhibited noticeable schistosomicidal activity, causing $100 \%$ mortality and decrease of motor activity of all adult male and female schistosomes (Table 1).

Schistosomicidal activities have been reported for several extracts from Rutaceae species or their secondary metabolites, mainly for alkaloids and coumarins [16-19]. In this regard, ethanolic extracts of Zanthoxylum naranjillo (Rutaceae) showed a significant activity on egg reduction of adult schistosomes [16], while ethanolic extracts of Citrus reticulata (Rutaceae) roots showed significant in vivo schistosomicidal activity [17]. Also, the alkaloid epiisopiloturine, isolated from the leaves of Pilocarpus microphyllus (Rutaceae), showed an in vitro effect on schistosomula and adult worms of $S$. mansoni, with no apparent cytotoxicity on mammalian cells [18]. Other compounds, such as furanocoumarins from the leaves of Citrus species (Rutaceae), have also been evaluated for their schistosomicidal activity [19].

After, Rg was chromatographed into four fractions, which were also assayed against schistosomes. In the schistosomicidal assay, when tested at $100 \mu \mathrm{g} / \mathrm{mL}$, only the 
TABle 1: In vitro schistosomicidal and cytotoxic activities of the crude extract of $R$. graveolens $(\mathbf{R g})$ and its fractions $(\mathbf{R g}-\mathbf{F C 1}, \mathbf{R g}-$ FC2, Rg-FC3, and Rg-FAE) against adult worms of S. mansoni incubated for $24 \mathrm{~h}$.

\begin{tabular}{|c|c|c|c|c|c|}
\hline \multirow[t]{2}{*}{ Groups } & \multicolumn{2}{|c|}{$\begin{array}{l}\text { Dead worms } \\
\qquad(\%)^{\mathrm{a}}\end{array}$} & \multicolumn{2}{|c|}{$\begin{array}{l}\text { Decrease of } \\
\text { motor } \\
\text { activity }(\%)^{\mathrm{a}}\end{array}$} & \multirow[t]{2}{*}{$\begin{array}{c}\text { Cytotoxicity } \mathrm{CC}_{50} \\
(\mu \mathrm{g} / \mathrm{mL})^{\mathrm{e}}\end{array}$} \\
\hline & Male & Female & Male & Female & \\
\hline Control $^{\mathrm{b}}$ & 0 & 0 & 0 & 0 & - \\
\hline $\begin{array}{l}0.5 \% \\
\text { DMSO }\end{array}$ & 0 & 0 & 0 & 0 & - \\
\hline $\mathrm{PZQ}^{\mathrm{c}}$ & 100 & 100 & 100 & 100 & - \\
\hline $\mathbf{R g}^{\mathrm{d}}$ & 100 & 100 & 100 & 100 & $>75$ \\
\hline Rg-FC1 ${ }^{d}$ & 0 & 0 & 0 & 0 & - \\
\hline Rg-FC2 ${ }^{\mathrm{d}}$ & 0 & 0 & 0 & 0 & - \\
\hline $\mathrm{Rg}-\mathrm{FC}^{\mathrm{d}}$ & 0 & 0 & 0 & 0 & - \\
\hline \multicolumn{6}{|l|}{ Rg-FAE } \\
\hline $100 \mu \mathrm{g} / \mathrm{mL}$ & 100 & 100 & 100 & 100 & $>75$ \\
\hline $50 \mu \mathrm{g} / \mathrm{mL}$ & 100 & 100 & 100 & 100 & - \\
\hline $25 \mu \mathrm{g} / \mathrm{mL}$ & 100 & 40 & 100 & 100 & - \\
\hline $12.5 \mu \mathrm{g} / \mathrm{mL}$ & 100 & 0 & 100 & 100 & - \\
\hline $6.25 \mu \mathrm{g} / \mathrm{mL}$ & 100 & 0 & 100 & 100 & - \\
\hline $3.125 \mu \mathrm{g} / \mathrm{mL}$ & 0 & 0 & 0 & 0 & - \\
\hline
\end{tabular}

${ }^{\mathrm{a}}$ Percentages relative to 20 worms investigated; ${ }^{\mathrm{b}} \mathrm{RPMI} 1640$; ${ }^{\mathrm{c}}$ tested at a concentration of $2 \mu \mathrm{M}$; ${ }^{d}$ tested at a concentration of $100 \mu \mathrm{g} / \mathrm{mL} ;{ }^{e} \mathrm{CC}_{50}$ values (50\% cytotoxicity concentration) on peritoneal macrophages.

fraction Rg-FAE was active (Table 1), causing 100\% mortality and decreasing motor activity after 24 hours of incubation, while fractions Rg-FC1, Rg-FC2, and Rg-FC3 did not show any activity for adult schistosomes, even at the highest concentration tested $(100 \mu \mathrm{g} / \mathrm{mL})$ (Table 1$)$. When analyzed at lower concentrations, Rg-FAE showed a pronounced schistosomicidal activity at 50, 25, 12.5, and $6.25 \mu \mathrm{g} / \mathrm{mL}$, causing significant decrease in motor activity and death of all male adult worms (Table 1). In contrast, when adult worms were maintained in the RPMI medium containing $0.5 \%$ DMSO, their appearance was similar to those maintained in the same medium without DMSO even after $72 \mathrm{~h}$ of incubation. During this period, all parasites revealed normal motor activity with natural peristalsis of the worm body. PZQ $(0.6248 \mu \mathrm{g} / \mathrm{mL}$ or $2 \mu \mathrm{M})$, used as the reference drug, reduced the motility and caused the death of all the parasites after $24 \mathrm{~h}$ of incubation.

Interestingly, at concentrations lower than $25 \mu \mathrm{g} / \mathrm{mL}$, marked schistosomicidal selectivity of Rg-FAE to male mortality was observed (Table 1 ). With respect to differential drug susceptibility between male and female schistosomes, several works have been reported showing that male worms of $S$. mansoni are often more susceptible than female worms [20-23]. Some compounds showed higher selectivity to male adult worms, such as $\mathrm{N}$-alkylated diamines and amino alcohols [20], while preferential killing of females was reported to other drugs [21, 22], including artesunate [23]. The fact that male schistosomes were more susceptible to Rg-FAE raised the question of whether the observed effect could be due to tegumental damages of compounds presented in $\mathbf{R g}$ FAE since tegument is extremely important to the parasite surviving both in vitro and in the host [24].

Considering the chemical characterization of the active fraction, qualitative chromatographic profiles of Rg-FAE were obtained by UPLC-ESI-QTOF-MS on the positive mode (Figure 1). The detailed information of each peak is listed on Table 2. Chemical structures of all identified compounds (Figure 2) in the active fraction (Rg-FAE) from $R$. graveolens were proposed through the interpretation of their mass spectra fragmentation patterns in comparison with those found in the literature and several online databases. A total of 11 alkaloids, along with one furanocoumarin, were identified on the basis of the contrasting cleavage rules, fragmentation ion pattern, and mass spectral data.

Mass data analysis showed that compounds $\mathbf{1}$ and $\mathbf{2}$ are quinoline alkaloids, presenting the same $\mathrm{m} / \mathrm{z}$ fragmentation pattern in the positive ion mode $(m / z 198,188,184,172$, and 132). Peak $1(m / z 286.0753)$ was suggested as 4-hydroxy-2decylquinoline (compound 1, Figure 2) and peak $2(\mathrm{~m} / z$ 300.0867 ) as 4-hydroxy-2-undecylquinoline (compound 2 , Figure 2) by comparing their mass spectra data with the literature [25].

Peaks 3 (4.81 $\mathrm{min})$ and 4 (5.36 $\mathrm{min})$ were isomers, showing the same molecular formula $\left(\mathrm{C}_{17} \mathrm{H}_{13} \mathrm{NO}_{3}\right)$, but displaying different MS/MS patterns. It was observed that the parent ion-radical $(m / z 280.0962)$ undergoes a loss of $\mathrm{CH}_{3}$, producing ion fragments at an $\mathrm{m} / z$ of 265.0717 [M$\left.\mathrm{CH}_{3}\right]^{+}$. Peak 3 also showed a loss of CO, giving the $\mathrm{m} / z$ of $237.0768\left[\mathrm{M}-\mathrm{CH}_{3}-\mathrm{CO}\right]^{+}$. As previously reported [26], the loss of $\mathrm{CO}$, from the molecular ion-radical, may lead to the formation of the indole scaffold peak. Finally, a loss of formaldehyde may take the mass fragment of $\mathrm{m} / z 207.0654$ $\left[\mathrm{M}-\mathrm{CH}_{2} \mathrm{O}\right]^{+}$. Mass fragmentation data for peak 3 are in agreement with the proposed structure of graveoline (compound 3, Figure 2) [27, 28]. Similarly, peak 4 showed a loss of an $\mathrm{OCH}_{3}$ methoxyl group, producing fragments at $\mathrm{m} /$ $z$ of $250.0862\left[\mathrm{M}-\mathrm{OCH}_{3}\right]^{+}$, suggesting that compound 4 may be graveolinine (Figure 2) [27, 28].

Peak $5\left(t_{\mathrm{R}}=5.72\right)$ showed an $[\mathrm{M}+\mathrm{H}]^{+}$ion at $\mathrm{m} / z$ 260.0886 and fragment ions at $m / z 245.0661\left[\mathrm{M}-\mathrm{CH}_{3}\right]^{+}$and $230.0430\left[\mathrm{M}-\mathrm{CH}_{3}\right]^{+}$in $\mathrm{MS}^{2}$ mode, suggesting consecutive losses of $15 \mathrm{u}$, which may be due to the loss of methyl groups from methoxyl groups. In addition, fragment ions were observed at $m / z 216\left[\mathrm{M}-\mathrm{CH}_{3}-\mathrm{CO}\right]^{+}$and $199\left[\mathrm{M}-\mathrm{CH}_{3}-\mathrm{H}_{2} \mathrm{O}-\right.$ $\mathrm{CO}]^{+}$. Molecular ion and fragmentation patterns are similar to those reported from literature $[28,29]$, indicating that compound $\mathbf{5}$ is skimmianine (Figure 2). Similarly, peak 6 $\left(t_{\mathrm{R}}=6.70\right)$ was identified as arborinine (Figure 2) based on its positive molecular ion at $[\mathrm{M}+\mathrm{H}]^{+}$of $\mathrm{m} / z 2286.1064$, as well as by MS/MS studies and fragmentation pattern of previous reports [27]. In addition, peak $7\left(t_{\mathrm{R}}=7.93\right)$ showed a molecular ion $[\mathrm{M}+\mathrm{H}]^{+}$at $m / z \quad 315.1586$ and an ion fragment $\left[\mathrm{M}-\left(\mathrm{CH}_{3}\right)_{2} \mathrm{COH}\right]^{+}$at $m / z 255$. Based on its fragmentation pattern along with previous literature data [30], this compound was identified as furanocoumarin chalepin (compound 7, Figure 2). 


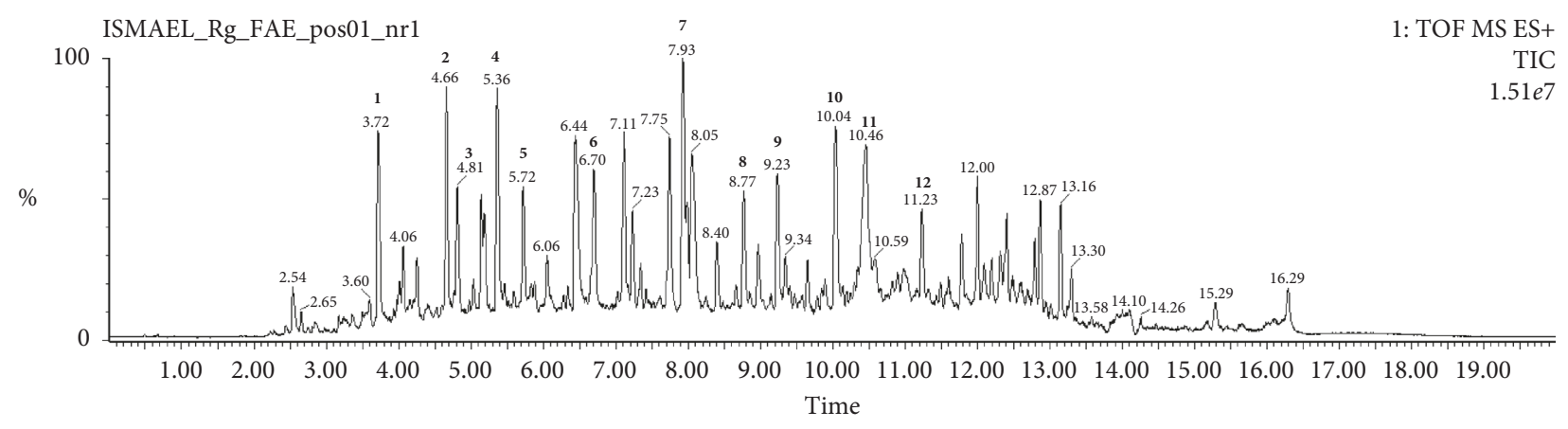

Figure 1: Typical UPLC-ESI-QTOF-MS chromatogram of $R$. graveolens fraction- (Rg-FAE-) positive mode.

TABle 2: Chemical characterization of Rg-FAE by UPLC-ESI-QTOF-MS.

\begin{tabular}{|c|c|c|c|c|c|c|}
\hline Peak & Proposed compounds & $\begin{array}{l}\mathrm{RT} \\
(\min )\end{array}$ & $\begin{array}{c}m / z \text { experimental } \\
{[\mathrm{M}+\mathrm{H}]^{+}}\end{array}$ & Main fragments via MS/MS & $\begin{array}{l}\text { Molecular } \\
\text { formula }\end{array}$ & References \\
\hline 1 & 4-hydroxy-2-decylquinoline & 3.72 & 286.0753 & $\begin{array}{c}198.0591,188.0791,184.0822,172.0781, \\
132.0473\end{array}$ & $\mathrm{C}_{19} \mathrm{H}_{27} \mathrm{NO}$ & {$[25]$} \\
\hline 2 & $\begin{array}{l}\text { 4-hydroxy-2- } \\
\text { undecylquinoline }\end{array}$ & 4.66 & 300.0867 & $198.0937,188.0735,184.0739,172.0781$ & $\mathrm{C}_{20} \mathrm{H}_{29} \mathrm{NO}$ & {$[25]$} \\
\hline 3 & Graveoline & 4.81 & 280.0962 & $265.0717,237.0768,207.0654$ & $\mathrm{C}_{17} \mathrm{H}_{13} \mathrm{NO}_{3}$ & {$[26,27]$} \\
\hline 4 & Graveolinine & 5.36 & 280.0962 & $265.0717,250.0862,222.0900$ & $\mathrm{C}_{17} \mathrm{H}_{13} \mathrm{NO}_{3}$ & {$[26,27]$} \\
\hline 5 & Skimmianine & 5.72 & 260.0886 & $245.0661,230.0430,216.0645,199.0618$ & $\mathrm{C}_{14} \mathrm{H}_{13} \mathrm{NO}_{4}$ & {$[28,29]$} \\
\hline 6 & Arborinine & 6.70 & 286.1064 & $\begin{array}{c}271.0844,253.0732,244.1687,225.0770 \\
197.0848,182.0599\end{array}$ & $\mathrm{C}_{16} \mathrm{H}_{15} \mathrm{NO}_{4}$ & {$[27]$} \\
\hline 7 & Chalepin & 7.93 & 315.1586 & $\begin{array}{c}273.1148,259.1003,255.1037,241.0889 \\
223.0753,213.0933,201.0573\end{array}$ & $\mathrm{C}_{19} \mathrm{H}_{22} \mathrm{O}_{4}$ & {$[30]$} \\
\hline 8 & $\begin{array}{l}\text { 1-methyl-2-nonyl-4(1H)- } \\
\text { quinolone }\end{array}$ & 8.77 & 286.2171 & $186.0907,173.0827$ & $\mathrm{C}_{19} \mathrm{H}_{27} \mathrm{NO}$ & {$[31]$} \\
\hline 9 & $\begin{array}{l}\text { 1-methyl-2-decyl-4(1H)- } \\
\text { quinolone }\end{array}$ & 9.23 & 300.2355 & $186.0907,173.0827$ & $\mathrm{C}_{20} \mathrm{H}_{29} \mathrm{NO}$ & {$[31]$} \\
\hline 10 & $\begin{array}{l}\text { 1-methyl-2-undecyl-4(1H)- } \\
\text { quinolone }\end{array}$ & 10.04 & 314.2481 & $186.0907,173.0827$ & $\mathrm{C}_{21} \mathrm{H}_{31} \mathrm{NO}$ & {$[31]$} \\
\hline 11 & $\begin{array}{l}\text { 1-methyl-2-dodecyl-4(1H)- } \\
\text { quinolone }\end{array}$ & 10.46 & 328.2617 & $186.0907,173.0827$ & $\mathrm{C}_{22} \mathrm{H}_{33} \mathrm{NO}$ & {$[31]$} \\
\hline 12 & Dihydroevocarpine & 11.23 & 342.2783 & $186.0907,173.0827$ & $\mathrm{C}_{23} \mathrm{H}_{35} \mathrm{NO}$ & [31] \\
\hline
\end{tabular}<smiles>[R]c1cc(O)c2ccccc2n1</smiles>

1. 4-hydroxy-2-decylquinoline: $\mathrm{R}=\mathrm{C}_{10} \mathrm{H}_{21}$

2. 4-hydroxy-2-undecylquinoline: $\mathrm{R}=\mathrm{C}_{11} \mathrm{H}_{23}$<smiles>Cn1c(-c2ccc3c(c2)OCO3)cc(=O)c2ccccc21</smiles>

3. Graveoline<smiles>Oc1cc(-c2ccc3c(c2)OCO3)nc2ccccc12</smiles>

4. Graveolinine<smiles>COc1ccc2c(OC)c3ccoc3nc2c1OC</smiles>

5. Skimmianine<smiles>COc1cc2c(c(O)c1OC)c(=O)c1ccccc1n2C</smiles>

6. Arborinine<smiles>C=CC(C)(C)c1cc2cc3c(cc2oc1=O)OC(C(C)(C)O)C3</smiles>

7. Chalepin<smiles>[R]c1cc(=O)c2ccccc2n1C</smiles>

8. 1-methyl-2-nonyl-4(1H)-quinolone: $\mathrm{R}=\mathrm{C}_{9} \mathrm{H}_{19}$ 9. 1-methyl-2-decyl-4(1H)-quinolone: $\mathrm{R}=\mathrm{C}_{10} \mathrm{H}_{21}$ 10. 1-methyl-2-undecyl-4(1H)-quinolone: $\mathrm{R}=\mathrm{C}_{11} \mathrm{H}_{23}$ 11. 1-methyl-2-dodecyl-4(1H)-quinolone: $\mathrm{R}=\mathrm{C}_{12} \mathrm{H}_{25}$ 12. Dihydroevocarpine: $\mathrm{R}=\mathrm{C}_{13} \mathrm{H}_{27}$

FIgURE 2: Chemical structures of compounds identified in Rg-FAE by UPLC-ESI-QTOF-MS analysis. 
According to literature, the McLafferty rearrangement occurs in quinolone alkaloids, leading to the formation of stable conjugate systems with ion fragments at $m / z 186$ and $m / z 173$ [32]. Therefore, $m / z 186$ and 173 ion fragments were used as diagnostic ion fragments to identify the quinolone alkaloids 8, 9, 10, 11, and 12 (Figure 2), which differ only in the number of carbons of the side chain. Then, comparing the mass spectra data with the literature [31], peaks $8(\mathrm{~m} / \mathrm{z}$ 286.2171), $9(\mathrm{~m} / z$ 300.2355), $10(\mathrm{~m} / z 314.2481), 11(\mathrm{~m} / z$ $328.2617)$, and $12(\mathrm{~m} / z$ 342.2783) were identified, respectively, as quinolone alkaloids 1-methyl-2-nonyl-4(1H)quinolone, 1-methyl-2-decyl-4(1H)-quinolone, 1-methyl-2undecyl-4(1H)-quinolone, 1-methyl-2-dodecyl-4(1H)-quinolone, and dihydroevocarpine, respectively. All of these quinolone alkaloids $(\mathbf{8}, \mathbf{9}, \mathbf{1 0}, \mathbf{1 1}$, and 12) were previously identified in $R$. graveolens [33].

In addition, the effect of the crude extract $\mathbf{R g}$ was evaluated against $L$. braziliensis. However, no significant antileishmanial results were found for $\mathbf{R g}\left(\mathrm{IC}_{50}>50 \mu \mathrm{g} / \mathrm{mL}\right)$ against $L$. braziliensis promastigotes (data not shown). In contrast, previous antileishmanial study with a crude extract of $R$. graveolens against L. amazonensis showed an inhibition of $74.4 \%$ in the number of promastigotes at $100 \mu \mathrm{g} / \mathrm{mL}$ [9]. On the contrary, the alkaloid-rich fraction Rg-FAE exhibited pronounced activity against $L$. braziliensis promastigotes in the antileishmanial assay, inhibiting the parasites growth in all concentrations, displaying an $\mathrm{IC}_{50}$ value of $5.90 \mu \mathrm{g} / \mathrm{mL}$, which was better than the reference drug miltefosine $\left(\mathrm{IC}_{50}\right.$ value of $12.09 \pm 0.017 \mu \mathrm{g} / \mathrm{mL}$ ). However, Rg-FAE showed low activity against intracellular amastigotes of L. braziliensis, diminishing the number of intracellular amastigotes by $26.58 \%$ at the maximum concentration used $(50 \mu \mathrm{g} / \mathrm{mL})$, while miltefosine showed an IC $_{50}$ value of $2.95 \pm 0.44 \mu \mathrm{g} / \mathrm{mL}$. This difference in sensibility between both stages of parasite could be due to biochemical targets, the rate of division, exposure, and inactivation into the parasitophorous vacuole or drug metabolism [34]. Although the antileishmanial effects of Rg-FAE cannot be considered as promising as well as the schistosomicidal activity, our data contribute with the ethnopharmacological use of a traditional medicinal plant from the Brazilian flora, such as $R$. graveolens, for the treatment of Leishmaniasis.

Moreover, considering their safety, Rg and Rg-FAE were also evaluated on cytotoxicity assay against murine macrophages. No significant toxic effects were observed for $\mathbf{R g}$ $\left(\mathrm{CC}_{50}>75 \mu \mathrm{g} / \mathrm{mL}\right.$ ) or Rg-FAE (CC ${ }_{50}$ value $\left.>75 \mu \mathrm{g} / \mathrm{mL}\right)$ to mammalian cells (Table 1) at concentrations that effectively kills worms of S. mansoni and promastigotes of L. braziliensis, giving support to its potential in identifying lead compounds for the development of novel antiparasitic drugs.

R. graveolens is an important medicinal plant that has been used as anthelmintic and to treat several diseases, such as leishmaniasis $[9,10]$. Alkaloids and coumarins, present in this plant species, have showed antileishmanial, antimalarial, and trypanocidal activities [35]. Among the compounds identified in Rg-FAE, several alkaloids, along with the identified furanocoumarin, could be related to the antiparasitic activity of this fraction.
Regarding the antiparasitic activity of Rg-FAE and its chemical composition, it was shown that 2-substituted quinoline alkaloids are highly active in vitro and in vivo against Leishmania sp. [36]. Also, some quinolone and quinoline alkaloids have showed some activity against larval [37] and adult worms [38], schistosomes. Since R. graveolens possesses a wide pharmacological potential and may have low toxicity [10], additional investigations are necessary to determine the antiparasitic potential of this species, especially of its active alkaloid-rich fraction Rg-FAE in treating schistosomiasis and leishmaniasis.

\section{Conclusions}

The present study has demonstrated, for the first time, that the $R$. graveolens extract and its alkaloid-rich fraction are active against adult worms of $S$. mansoni in vitro, with no cytotoxicity on mammalian cells. Eleven alkaloids, together with a furancoumarin, were identified by UPLC-ESI-QTOFMS analysis as constituents of the active fraction Rg-FAE. Our findings open the route to further antiparasitic studies with the active fraction and its isolated compounds, especially alkaloids.

\section{Data Availability}

The data used to support the findings of this study are included within the article.

\section{Conflicts of Interest}

The authors declare that there are no conflicts of interest.

\section{Acknowledgments}

The authors are grateful to FAPEMIG (grant numbers: APQ 02015/14, PPM-00296-16, and BPD 00284-14), FAPESP (grant number: 2016/22488-3), and CNPq (grant number: 487221/2012-5) for financial support, as well as to CAPES, $\mathrm{PIBIC/CNPq/UFJF}$, and CNPq for fellowships. The authors also are grateful to CENTRALBIO, Carolina M. Gasparetto (Centralbio/Faculdade de Farmácia/UFJF) and Lorena R. Riani for technical assistance with UPLC-ESI-QTOF-MS.

\section{References}

[1] World Health Organization (WHO), "Investing to overcome the global impact of neglected tropical diseases," Third WHO Report on Neglected Diseases, World Health Organization (WHO), Geneva, Switzerland, 2015.

[2] GBD Collaborators, "Global, regional, and national incidence, prevalence, and years lived with disability for 328 diseases and injuries for 195 countries, 1990-2016: a systematic analysis for the Global Burden of Disease Study 2016," The Lancet, vol. 390, no. 10100, pp. 1211-1259, 2017.

[3] Ministério da Saúde (BR) and Secretaria de Vigilância em Saúde, Coordenação-Geral de Desenvolvimento da Epidemiologia em Serviços. Guia de Vigilância em Saúde, Ministério da Saúde, Brasília, Brazil, 2017.

[4] E. M. Lago, R. P. Xavier, T. R. Teixeira, L. M. Silva, A. A. da Silva Filho, and J. de Moraes, "Antischistosomal agents: state 
of art and perspectives," Future Medicinal Chemistry, vol. 10, no. 1, pp. 89-120, 2018.

[5] J. P. B. De Menezes, C. E. S. Guedes, A. L. d. O. A. Petersen, D. B. M. Fraga, and P. S. T. Veras, "Advances in development of new treatment for leishmaniasis," BioMed Research International, vol. 2015, Article ID 815023, 11 pages, 2015.

[6] A. S. Nagle, S. Khare, A. B. Kumar et al., "Recent developments in drug discovery for leishmaniasis and human African trypanosomiasis," Chemical Reviews, vol. 114, no. 22, pp. 11305-11347, 2014.

[7] M. Ratheesh and A. Helen, "Anti-inflammatory activity of Ruta graveolens Linn on carrageenan-induced paw edema in rats," African Journal Biotechnology, vol. 6, no. 10, pp. 1209-1211, 2007.

[8] S. K. Raghav, B. Gupta, A. Shrivastava, and H. R. Das, "Inhibition of lipopolysaccharide-inducible nitric oxide synthase and IL- $1 \beta$ through suppression of NF- $\kappa$ B activation by $3-\left(1^{\prime}-\right.$ $1^{\prime}$-dimethyl-allyl)-6-hydroxy-7-methoxy-coumarin isolated from Ruta graveolens L.," European Journal of Pharmacology, vol. 560, no. 1, pp. 69-80, 2007.

[9] A. C. De Queiroz, T. L. Dias, C. B. Da Matta et al., "Antileishmanial activity of medicinal plants used in endemic areas in northeastern Brazil," Evidence-Based Complementary and Alternative Medicine, vol. 2014, Article ID 478290, 9 pages, 2014.

[10] S. Malik, D. F. C. Moraes, F. M. M. Do Amaral, and M. N. S. Ribeiro, "Ruta graveolens: phytochemistry, pharmacology, and biotechnology," in Transgenesis and Secondary Metabolism, pp. 177-204, Springer, Cham, Switzerland, 2017.

[11] J. De Moraes, C. Nascimento, L. F. Yamaguchi, M. J. Kato, and E. Nakano, "Schistosoma mansoni: in vitro schistosomicidal activity and tegumental alterations induced by piplartine on schistosomula," Experimental Parasitology, vol. 132, no. 2, pp. 222-227, 2012.

[12] V. S. Carrara, S. C. H. Vieira, R. G. De Paula et al., "In vitro schistosomicidal effects of aqueous and dichloromethane fractions from leaves and stems of Piper species and the isolation of an active amide from P. amalago L. (Piperaceae)," Journal of Helminthology, vol. 88, no. 3, pp. 321-326, 2014.

[13] L. M. S. De Almeida, L. S. A. De Carvalho, M. C. Gazolla et al., "Flavonoids and sesquiterpene lactones from Artemisia absinthium and Tanacetum parthenium against Schistosoma mansoni worms," Evidence-Based Complementary and Alternative Medicine, vol. 2016, Article ID 9521349, 9 pages, 2016.

[14] L. M. R. Antinarelli, I. d. O. Souza, N. Glanzmann et al., "Aminoquinoline compounds: effect of 7-chloro-4-quinolinylhydrazone derivatives against Leishmania amazonensis," Experimental Parasitology, vol. 171, pp. 10-16, 2016.

[15] P. M. Cheuka, G. Moyoka, P. Mutai, and K. Chibale, "The role of natural products in drug discovery and development against neglected tropical diseases," Molecules, vol. 22, no. 1, p. E58, 2017.

[16] C. G. Braguine, E. S. Costa, L. G. Magalhães et al., "Schistosomicidal evaluation of Zanthoxylum naranjillo and its isolated compounds against Schistosoma mansoni adult worms," Zeitschrift fur Naturforschung. C, Journal of Bioscience, vol. 64, no. 11-12, pp. 793-797, 2009.

[17] M. A. Hammed and M. H. Hetta, "Efficacy of Citrus reticulata and Mirazid in treatment of Schistosoma mansoni," Memórias do Instituto Oswaldo Cruz, vol. 100, no. 7, pp. 771-778, 2005.

[18] L. M. Veras, M. A. Guimaraes, Y. D. Campelo et al., "Activity of epiisopiloturine against Schistosoma mansoni," Current Medicinal Chemistry, vol. 19, no. 13, pp. 2051-2058, 2012.
[19] E. G. Haggag, S. M. Abdel Wahab, S. M. El-Zalabany, E. A. A. Moustafa, E. M. El-Kherasy, and T. J. Mabry, "Coumarin content and anti-bilharzial activity of extracts of leaves of Citrus aurantifolia (lime) and Citrus limonia (lemon)," Asian Journal Chemistry, vol. 10, no. 4, p. 583, 1998.

[20] F. S. Fernandes, C. O. Rezende Junior, T. S. Fernandes et al., "Anthelmintic effects of alkylated diamines and amino alcohols against Schistosoma mansoni," BioMed Research International, vol. 2013, Article ID 783490, 9 pages, 2013.

[21] S. C. De Araujo, A. C. A. de Mattos, H. F. Teixeira, P. M. Z. Coelho, D. L. Nelson, and M. C. de Oliveira, "Improvement of in vitro efficacy of a novel schistosomicidal drug by incorporation into nanoemulsions," International Journal of Pharmaceutics, vol. 337, no. 1-2, pp. 307-315, 2007.

[22] M. L. de Oliveira Penido, P. M. Zech Coelho, R. T. de Mello et al., "Antischistosomal activity of aminoalkanethiols, aminoalkanethiosulfuric acids and the corresponding disulfides," Acta Tropica, vol. 108, no. 2-3, pp. 249-255, 2008.

[23] Y. Mitsui, M. Miura, and Y. Aoki, "In vitro effects of artesunate on the survival of worm pairs and egg production of Schistosoma mansoni," Journal of Helminthology, vol. 83, no. 1, pp. 7-11, 2009.

[24] T. Manneck, Y. Haggenmüller, and J. Keiser, "Morphological effects and tegumental alterations induced by mefloquine on schistosomula and adult flukes of Schistosoma mansoni," Parasitology, vol. 137, no. 1, pp. 85-98, 2010.

[25] F. Lépine, S. Milot, E. Déziel, J. He, and L. G. Rahme, "Electrospray/mass spectrometric identification and analysis of 4-hydroxy-2-alkylquinolines (HAQs) produced by Pseudomonas aeruginosa," Journal of the American Society for Mass Spectrometry, vol. 15, no. 6, pp. 862-869, 2004.

[26] J. Reisch, R. Pagnucco, and N. Jantos, "Mass spectrometric studies of quinoline alkaloids-I. Some 2-alkyl(aryl)-4-quinolones," Phytochemistry, vol. 7, no. 6, pp. 997-1003, 1968.

[27] M. Kacem, I. Kacem, G. Simon et al., "Phytochemicals and biological activities of Ruta chalepensis L. growing in Tunisia," Food Bioscience, vol. 12, pp. 73-83, 2015.

[28] F. O’Donnell, V. N. Ramachandran, W. F. Smyth, C. J. Hack, and E. Patton, "A study of the analytical behaviour of selected synthetic and naturally occurring quinolines using electrospray ionisation ion trap mass spectrometry, liquid chromatography and gas chromatography and the construction of an appropriate database for quinoline characterization," Analytica Chimica Acta, vol. 572, no. 1, pp. 63-76, 2006.

[29] D. J. Cuthbertson, S. R. Johnson, J. Piljac-Žegarac et al., "Accurate mass-time tag library for LC/MS-based metabolite profiling of medicinal plants," Phytochemistry, vol. 91, pp. 187-197, 2013.

[30] J. S. Richardson, G. Sethi, G. S. Lee, and S. N. Malek, "Chalepin: isolated from Ruta angustifolia L. pers induces mitochondrial mediated apoptosis in lung carcinoma cells," BMC Complementary and Alternative Medicine, vol. 16, no. 1, p. 389, 2016.

[31] S. Yang, M. Tian, L. Yuan et al., "Analysis of E. rutaecarpa alkaloids constituents in vitro and in vivo by UPLC-Q-TOFMS combined with diagnostic fragment," Journal of Analytical Methods in Chemistry, vol. 2016, Article ID 4218967, , 2016.

[32] N. Zhao, Z.-L. Li, D.-H. Li et al., "Quinolone and indole alkaloids from the fruits of Euodia rutaecarpa and their cytotoxicity against two human cancer cell lines," Phytochemistry, vol. 109, pp. 133-139, 2015.

[33] I. Kostova, A. Ivanova, B. Mikhova, and I. Klaiber, "Alkaloide und cumarine aus Ruta graveolens," Monatshefte fuer Chemiel Chemical Monthly, vol. 130, no. 5, pp. 703-707, 1999. 
[34] P. Escobar, S. Matu, C. Marques, and S. L. Croft, "Sensitivities of Leishmania species to hexadecylphosphocholine (miltefosine), ET-18-OCH3 (edelfosine) and amphotericin B," Acta Tropica, vol. 81, no. 2, pp. 151-157, 2002.

[35] E. S. K. Mwangi, J. M. Keriko, A. K. Machocho et al., "Antiprotozoal activity and cytotoxicity of metabolites from leaves of Teclea trichocarpa," Journal of Medicinal Plants Research, vol. 4, no. 9, pp. 726-731, 2010.

[36] K. A. Reynolds, W. A. Loughlin, and D. J. Young, "Quinolines as chemotherapeutic agents for leishmaniasis," Mini-Reviews in Medicinal Chemistry, vol. 13, no. 5, pp. 730-743, 2013.

[37] S. Perrett and P. Whitfield, "Atanine (3-dimethylallyl-4methoxy-2-quinolone), an alkaloid with anthelmintic activity from the Chinese medicinal Plant, Evodia rutaecarpa," Planta Medica, vol. 61, no. 3, pp. 276-278, 1995.

[38] S. El Bardicy, I. El Sayed, F. Yousif et al., "Schistosomicidal and molluscicidal activities of aminoalkylamino substituted neo- and norneocryptolepine derivatives," Pharmaceutical Biology, vol. 50, no. 2, pp. 134-140, 2012. 


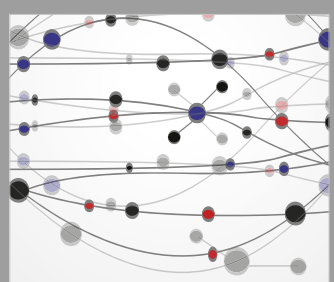

The Scientific World Journal
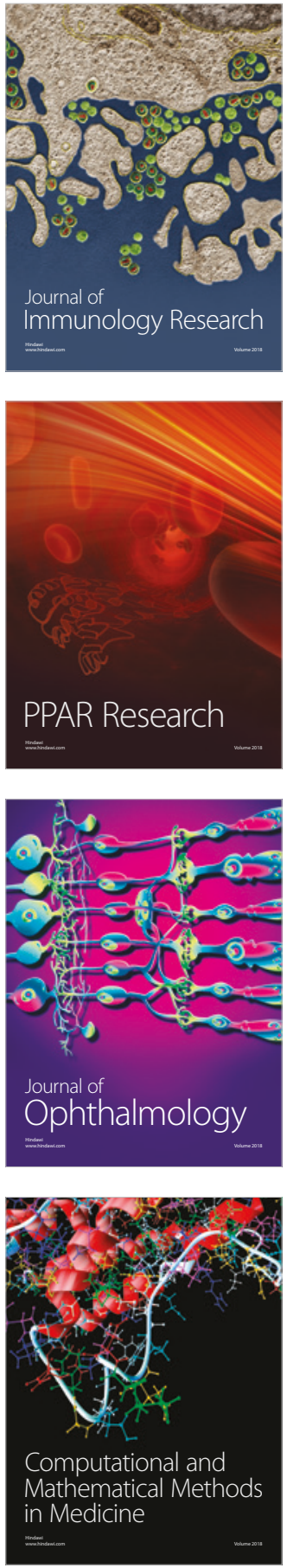

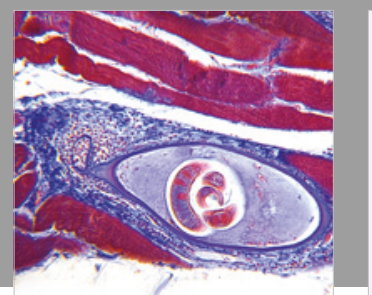

Gastroenterology Research and Practice

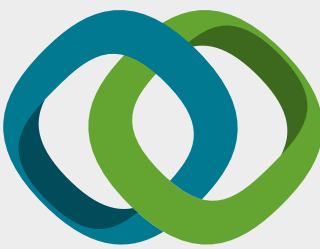

\section{Hindawi}

Submit your manuscripts at

www.hindawi.com
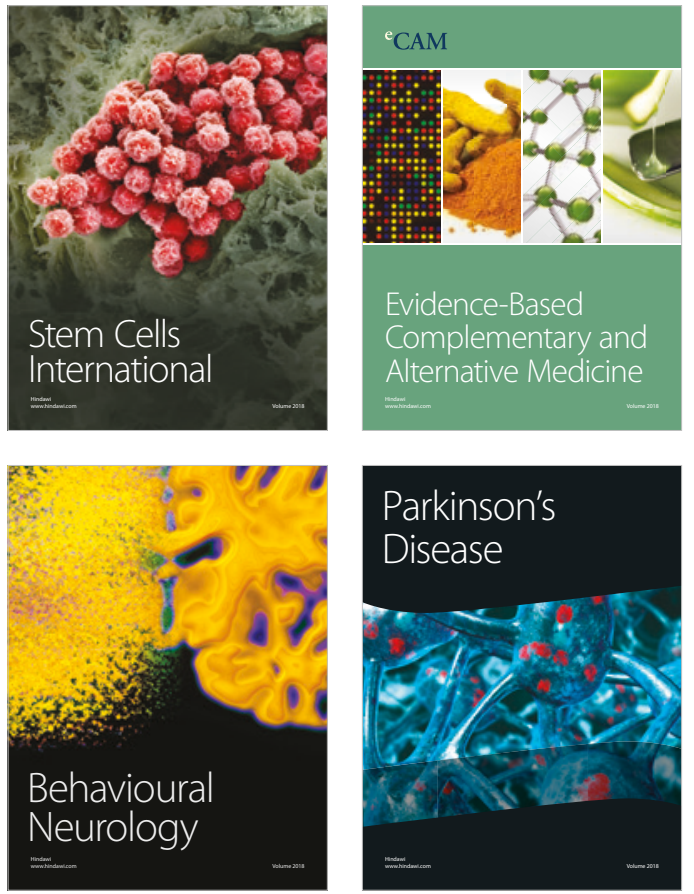

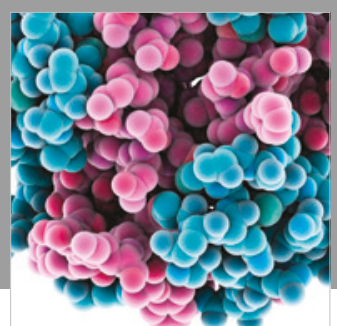

ournal of

Diabetes Research

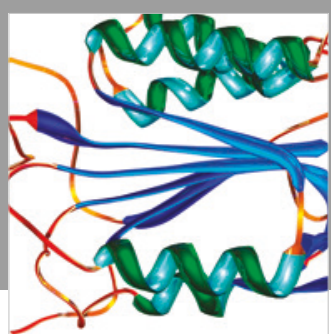

Disease Markers
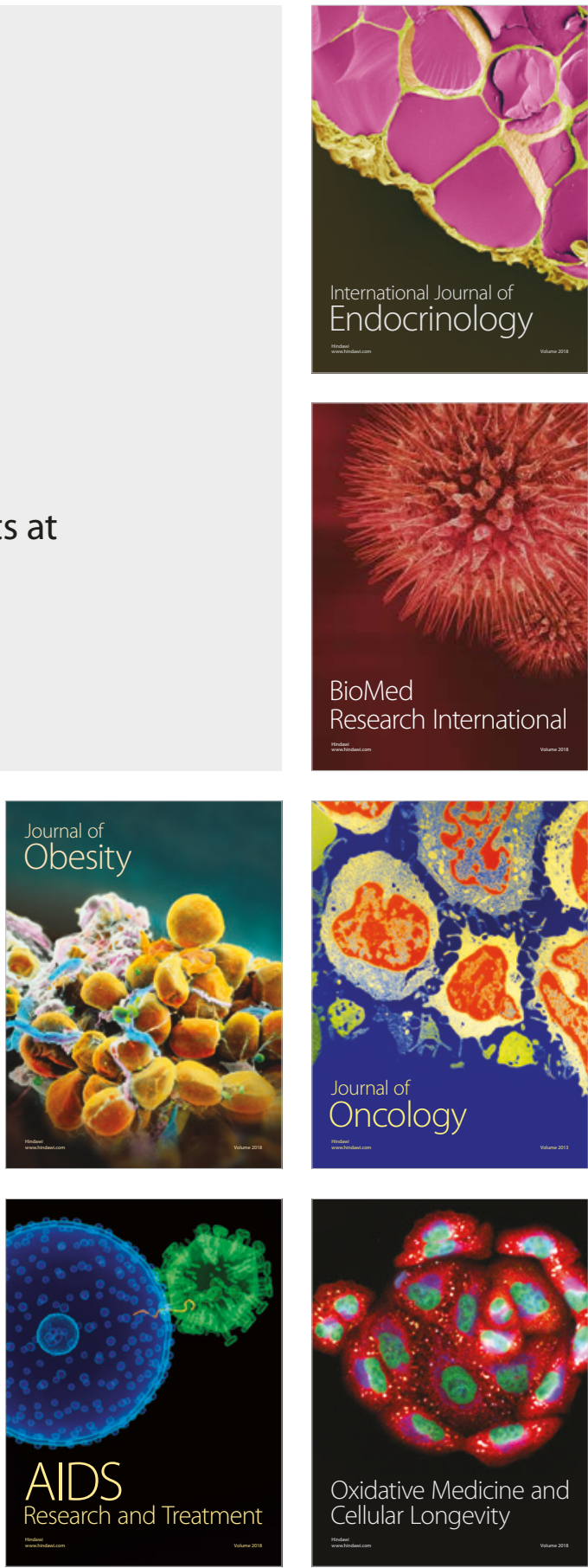